\title{
Artivismos «Undocuqueer» Latino nos EUA: Queer, indocumentados, SEm MEDO E SEM REMORSOS.
}

Glauco B. Ferreira

UFSC, Florianópolis, SC, Brasil ${ }^{1}$

Este ensaio trata das performances artivistas em torno de movimentos pró-imigratórios nos Estados Unidos, mais especificamente na região da Baía de San Francisco, abordando particularmente o projeto "I am Undocuqueer", do artivista latino-estadunidense de origem mexicana Julio Salgado. Busca-se ressaltar as maneiras locais pelas quais o contemporâneo movimento social em torno dos direitos imigratórios nos EUA catalisa também outras formas de pensar sobre arte e política, principalmente entre populações latinas em seu processo de organização social e cultural, enfocando os movimentos e individualidades que se autodefinem como queer of color. Neste contexto, individuos articulam sentidos locais para 0 artivismo que desenvolvem - profundamente envolvidos na reclamação de direitos civis - e comprometidos em abrir espaços para a configuração de distintos processos identitários interseccionais, além de fomentarem outras discussões sobre o que seja a "nação americana", remetendo a debates abrangentes sobre cidadania no século XXI.

Palavras-chaves: movimentos sociais contemporâneos, queer of color, artivismo, modos de subjetivação

1 Glauco B. Ferreira é antropólogo, artista visual e arte/educador. Graduado em artes plásticas pela Universidade do Estado de Santa Catarina; mestre em Antropologia Social pela Universidade Federal de Santa Catarina, em Florianópolis, Santa Catarina, Brasil. É doutorando em Antropologia Social na UFSC, com bolsa de pesquisa CAPES (D/S). Foi Visiting Scholar na University of California at Berkeley (EUA). Integra o Núcleo de Antropologia do Contemporâneo (TRANSES/UFSC), sob coordenação da professora Sônia W. Maluf, no PPGAS/UFSC. Contato: glaucoart@gmail.com; página pessoal: glaucoferreira.com 


\section{INTRODUÇÃo}

Entre os anos de 2013 e 2014 realizei trabalho de campo junto a uma organização não governamental sem fins lucrativos, ${ }^{2}$ que tinha como foco um trabalho de formação política e artística entre a população que se autodefine como queer of color na região da Baía de San Francisco. Pude assim acessar variadas iniciativas na região relacionadas aos artivismos (um neologismo que aglutina arte e ativismo) que lá se desenvolviam e que teciam relações com diferentes movimentos sociais e organizações políticas (Ferreira 2012: 69). Dentre as atividades, eventos e mobilizações naquela região dos Estados Unidos se realçam justamente algumas das ações de grupos artivistas autodefinidos como queers of color, que assinalam de maneira irreverente, artística e poderosa algumas importantes distinções no interior dos movimentos $\mathrm{LGBTQI}^{4}$ e de imigrantes no país.

Ao longo de minha investigação de campo, ${ }^{5}$ os trabalhos do artista latino-estadunidense de origem mexicana Julio Salgado chamavam a atenção justamente por sua vinculação e relacionamento com diferentes movimentos sociais e em especial com as ações de imigrantes em torno da ação legislativa DREAM Act. Seus projetos artísticos assinalavam diferenças e interessantes intersecções no interior dos movimentos pró-imigratórios, especialmente no que se refere às demandas de populações jovens, queers e indocumentadas que também se organizam através destas mobilizações. Abordarei aqui o projeto de Julio Salgado intitulado "I am Undocuqueer" que se desenvolveu em uma conjuntura nacional de debates acalorados sobre o DREAM Act e influenciaram outras discussões sobre a definição do que fossem os cidadãos americanos/estadunidenses e a abrangência de seus direitos civis.

Dessa forma, proponho abrir espaço para pensarmos sobre as diferentes maneiras pelas quais arte e política podem entrecruzar-se e como produzem e simultaneamente potencializam outras reflexões locais sobre diferentes intersecções e marcadores sociais de diferença, sejam estes de classe, gênero, sexualidade e status legal, na fabricação de imagens e de outras criações artísticas. A incorporação consciente e a denominação de suas atividades como 'artivismo' também propiciam contexto para refletirmos sobre a plasticidade deste conceito nos usos que faz o artista na criação de suas obras e em seu engajamento político e social ${ }^{6}$.

2 Queer Women of Color Media Arts Project (QWOCMAP) é a organização não-governamental com a qual realizei trabalho de campo por um ano. O coletivo organiza e forma mulheres e pessoas que se autodefinem como queer, gender nonconforming e transgêneros num projeto de treinamento cinematográfico.

3 "Queers of Color" poderia ser traduzido como "queer de cor". Esta expressão ressalta os processos identitários de sujeitos nas intersecções entre gênero, "raça/etnicidade", sexualidades, classe social e status migratório. Os sujeitos queer questionam o binarismo de gênero. A expressão "of color" ("de cor") sinaliza a incorporação de marcadores de diferença relacionados às variadas classificações raciais e étnicas não-brancas nos EUA, nas quais muitos destes sujeitos se reconhecem. Todas as traduções existentes neste ensaio são minhas.

4 Sigla que representa Lésbicas, Gays, Bissexuais, Transgêneros, Queers e Intersexos.

5 Desenvolvi trabalho de campo entre 2013 e 2014, ao mesmo tempo em que participava da vida acadêmica da University of California at Berkeley como Visiting Scholar Researcher sob supervisão da Dra. Trint T. Minh-há. Desenvolvo minha tese de doutorado em Antropologia Social na Universidade Federal de Santa Catarina. As discussões neste ensaio são reflexões ainda em processo de elaboração. Agradeço a CAPES pelo financiamento à pesquisa através da bolsa PDSE (processo 8133-13-1).

6 Gostaria de agradecer às contribuições e sugestões dos editores deste dossiê temático e dos pareceristas sobre este artigo, que auxiliaram imensamente no aperfeiçoamento da forma que este texto tomou em sua versão final. 


\section{O MOVIMENTO PRÓ-IMIGRAÇÃo EM TORNO DO DREAM ACT}

O DREAM Act (Development, Relief, and Education for Alien Minors) foi uma proposta legislativa primeiramente introduzida no Senado Estadunidense em 2001 e previa o suprimento de vistos de residência condicionais a certos imigrantes que tivessem se graduado no ensino médio (high school) já em terras americanas, que tivessem chegado aos Estados Unidos como menores de idade e que tivessem vivido no país por pelo menos cinco anos antes do anúncio e aprovação da proposta de lei. Ao longo dos anos 2000, uma forte mobilização se desenvolveu, especialmente entre a grande população de jovens imigrantes e estudantes universitários, que diferentemente se seus pais e avós - que também tinham emigrado e mantinham certa reserva a respeito de seu status legal enquanto imigrantes indocumentados nos EUA - começavam a assumir uma posição de enfrentamento e de reclame de direitos civis no contexto das políticas imigratórias vigentes nos Estados Unidos.

Neste contexto, o jornalista latino e indocumentado Jose Antonio Vargas fundou a Define American, ${ }^{7}$ uma organização sem fins lucrativos dedicada a modificar e reenquadrar as conversações e debates nacionais nos Estados Unidos a respeito da política imigratória de sucessivos mandatos e instâncias governamentais estadunidenses. Um jornalista experiente e ganhador do prêmio Pulitzer, Vargas ganhou popularidade na mídia norte-americana e global ao divulgar "My Life as an Undocumented Immigrant", ${ }^{8}$ artigo presente na Nerw York Times Magazine em junho de 2011. No artigo ele revelava pela primeira vez sua situação enquanto imigrante indocumentado, de origem mexicana, problematizando e ampliando o debate sobre imigração no país e relacionando sua 'condição' trabalhista e seu status legal com outros debates sobre as identidades e dificuldades enfrentadas pelos imigrantes no país. Isso ocorria em uma conjuntura na qual o mandato do presidente Barack Obama sinalizava mudanças nas discussões políticas em torno das demandas e reconhecimento das diferentes populações imigrantes, algo que criava expectativas de que finalmente alguns avanços surgissem em termos legais e influenciassem as condições de vida e reconhecimento estatal desta parcela da população no país.

O artigo influenciou discussões públicas a respeito dos imigrantes no país e entusiasmou também as iniciativas de um movimento nacional de estudantes imigrantes indocumentados, para que "saíssem das sombras" ${ }^{9}$ e começassem a discutir publicamente o que chamavam de seu 'status imigratório', isto é, sua situação enquanto pessoas que não possuíam a documentação governamental oficial. Muitas destas pessoas se identificavam enquanto estadunidenses/americanos mesmo que não tivessem documentos oficiais, resistindo e problematizando concepções muito persistentes no país segundo as quais os imigrantes não sejam "legítimos" "cidadãos americanos", argumento esse que se baseia unicamente em termos jurídicos para criar um tipo de distinção que é em si mesma exclusiva e um tanto xenófoba.

7 Acesse o site da organização: http://www.defineamerican.com/. Acessado em julho de 2015.

8Acessível em: http://www.nytimes.com/2011/06/26/magazine/my-life-as-an-undocumented-immigrant.html?pagewanted=all\&_r=1. Acessado em julho de 2015.

9 Ao discutirem publicamente seu status imigratório e "saírem das sombras" estes sujeitos fazem alusão e traçam um paralelo com as iniciativas de coming out (sair do armário) incentivadas pelo movimento LGBTQI. Esta iniciativa visa a discussão pública como um ato de resistência em arenas políticas variadas. Embora não se trate de um mesmo movimento de discussão pública, estes duas atitudes de resistência se assemelham em muitos sentidos. Como veremos a seguir, muitos dos jovens indocumentado/as e queer narram suas experiências (seja na vivência de sua sexualidade ou de sua condição como indocumentados) como processos de identidade e de subjetivação que estão entrecruzados e que não poderiam ser necessariamente hierarquizados. 
Muitas destas pessoas, sendo imigrantes de segunda e terceira geração, isto é, filhos e netos de imigrantes de primeira geração, jamais viveram em outro lugar que não fosse os Estados Unidos. Isso provocava uma conjuntura problemática na qual alguns daqueles que se identificavam enquanto americanos tinham documentos governamentais oficiais - o que lhes garante "existência oficial" perante o Estado e lhes outorga direitos civis variados - enquanto estes 'outros' americanos não eram reconhecidos legalmente e não tinham os mesmos benefícios sociais e direitos. Muitos destes sujeitos enfrentam assim grandes dificuldades em diversas instâncias nas quais os documentos são exigidos, tal como no mercado empregatício, em algumas instituições governamentais e em locais de fiscalização que exigem documentos, tais como aeroportos e alfândegas, por exemplo.

Nas margens e através destes movimentos se devolveram então outras discussões não somente abordando a situação legal migratória desta parcela da população americana, mas também produzindo espaços para uma modificação na maneira como os próprios imigrantes enxergam a si mesmos em termos de identificação e subjetividade. Nessa conjuntura política já não se partia de um ponto de vista no qual se iniciavam os debates tal como se estas pessoas fossem imigrantes ilegais (illegal aliens) - maneira pela qual alguns se referiam à população imigrante nos EUA e que estava anteriormente bastante relacionada a processos de culpabilização e marginalização social destas populações - e passou-se a discutir então outras implicações sociais e econômicas, ao se considerarem os processos e as políticas identitárias imigrantes em uma matriz que toma identidades de uma forma interseccional e de forma mais positiva. Estas novas formas de enquadrar o debate sobre imigração passou a considerar, no contexto de um movimento social nacional pró-imigratório de repercussão internacional, certas discussões sobre as identidades ali representadas no qual o status de imigração era incorporado como parte das individualidades e subjetividades envolvidas, considerando aí as diferentes posicionalidades abarcadas.

Mesmo sem documentos, estas pessoas compreendem a si mesmas como "parte" dos Estados Unidos em suas diferentes acepções enquanto nação e cultura. Este movimento se dá exatamente por que muitas destas pessoas ali sempre viveram ou então porque ali foi onde viveram grande parte das suas vidas, passando assim a se compreenderem como americanos/estadunidenses mesmo que indocumentados. Ao reivindicarem a nacionalidade e a cultura estadunidense, como parte de suas identificações subjetivas e como espaço geográfico ao qual chamam de lar, os processos de subjetivação envolvidos se tornavam mais complexos, justamente por não tomarem somente as origens étnicas e/ou nacionais ou somente os aspectos classificatórios raciais mais evidentes e vigentes no país, buscando incluir o status imigratório como algo que molda subjetividades e maneiras de estar no mundo. Ser indocumentado, em muitas instâncias, aciona sentimentos de estranheza que não são experimentados por outros 'cidadãos americanos', que na maioria das vezes desfrutam de privilégios e direitos civis tomados quase sempre como algo dado e generalizado para a maioria da população pelas pessoas que desfrutam destes privilégios. Nesta dinâmica se produzem variadas situações nas quais atividades aparentemente corriqueiras e diárias se tornam um tanto mais complexas para as pessoas indocumentadas.

O sentimento de estranheza (awkwardness), presente em diversas situações em que estes sujeitos são levados a discutir publicamente seu status enquanto imigrantes sem documentos oficiais se tornam também algo sobreposto nestes processos de subjetivação. Estes elementos de estranheza são incorporados aos processos identitários e que se desenvolvem na intersecção de diferentes marcadores de diferença. Considero que ali muitas vezes as identidades não são tomadas de forma substancial, mas sim como processos desessencializados que se aglutinam 
de forma contingente e estratégica levando em consideração as posicionalidades e os contextos sociais, culturais e históricos nos quais se desdobram (Hall 2000: 104-108).

Estes processos identitários e movimentos de resistência passam então a influenciar uma conjuntura na qual, sem medo de reclamar seu status como imigrantes indocumentados, novos protagonistas, geralmente jovens estudantes recém formados em cursos universitários, começam a realizar discussões mais aprofundadas entre o movimento pró-imigratório nos EUA sobre as diversas identidades ali catalisadas. Estes processos de identificação estão profundamente influenciados por situações de precariedade legal e trabalhista aos quais muitos destes sujeitos estão submetidos, ao não terem outros modos de acessar benefícios governamentais trabalhistas e melhores condições de emprego.

Estes novos protagonistas são também pessoas que se inserem de maneira corajosa no debate político nacional sobre as políticas imperialistas estadunidenses, questionando as pilhagens econômicas e seus efeitos em diferentes regiões do mundo. Neste movimento são também estes os sujeitos que alertam e personificam através de suas próprias histórias de vida as conseqüências geopolíticas implicadas nas ofensivas imperialistas, que ocasionam diversas vezes processos de deslocamento populacional e fenômenos migratórios massivos. São estas pessoas que buscam melhores condições de vida saindo de seus locais de origem na busca do 'sonho americano' e que, nessa nova situação, passam também a personificar e questionar certos limites das conformações dos Estados-nações contemporâneos.

Enquanto campo de forças políticas multifacetadas, o Estado-nação é também arena de disputas e reconhecimento de direitos, uma vez que as presenças de populações imigrantes (principalmente das populações latinas e asiáticas nos Estados Unidos) também afetam os cenários políticos e eleitorais e as contendas mais amplas pela ampliação dos limites do que seja essa nação. Estas dinâmicas sociais afetam as representações sobre a nação estadunidense, suscetíveis às disputas discursivas através de massivas manifestações de rua. Como veremos, essas mobilizações contestam as condições de precariedade nas quais muitos dos sujeitos imigrantes conformam suas subjetividades na era do neoliberalismo.

\section{"QueERIZANDO" E SE (DES)IDENTIFICANDO COM A NAÇÃo}

Foi também Jose Antonio Vargas um dos responsáveis por popularizar nacionalmente o termo 'undocumented americans', após um artigo e história de capa na revista TIME. O artigo, intitulado ' $W E$ ARE AMERICANS* ('Just not legally) $)^{10}$ ' trazia como material e fotografia de capa os relatos e experiências de 36 DREAMers $^{11}$ - pessoas nascidas em 15 diferentes países, mas que reconheciam os Estados Unidos como seu lar e que eram elegíveis às implicações do

10 Em tradução: 'NÓS SOMOS AMERICANOS* ("somente não legalmente)'. Acesse a matéria:: http://time. com/2987974/jose-vargas-detained-time-cover-story/. Acessado em maio de 2015.

11 Acesse a matéria e vídeo com depoimentos destas pessoas neste link, da revista TIME: http://ideas.time. com/2012/06/14/inside-the-world-of-the-illegal-immigrant/ (acessado em maio de 2015). O termo DREAMers, traduzido: "SONHAdores", se refere aos imigrantes elegíveis pelo DREAM Act. Depois de publicada a matéria na revista TIME o Department of Homeland Security estadunidense anunciou que não deportaria jovens elegíveis pelo DREAM Act. Aqueles elegíveis receberiam permissões oficiais de trabalho nos EUA. Um vídeo nesta matéria conta com depoimento de imigrantes e de Julio Salgado (com título: "Undocumented Americans: Julio Salgado"): https:// www.youtube.com/watch?v=tRQHGMmtP1w. Acessado em maio de 2015. 
ato legislativo em questão. No artigo Jose Antonio Vargas abordava e descrevia o movimento dos mais 11,5 milhões de imigrantes indocumentados no país na sua luta por reconhecimento estatal, ao mesmo tempo em que tratava de forma aberta e positiva a respeito das discussões sobre o status de imigrantes indocumentados e a necessidade de "sair das sombras" como forma de influenciar a administração governamental de modo a obter conquistas civis.

Grande parte do ativismo em torno das políticas pró-imigratórias, principalmente na juventude universitária protagonista deste movimento social nos últimos anos, articula-se e organiza também por meio das ferramentas virtuais de interação, tomando como parte de suas iniciativas a comunicação através de redes sociais, blogs e outros fóruns virtuais para sua coordenação nacional. Foi através de vídeos produzidos para a internet ${ }^{12}$ que uma marcha nacional, organizada em março de 2011, foi divulgada, buscando atrair aqueles que, tal como seu slogan ressaltava, eram indocumentados, sem medo e sem remorsos para saírem às ruas reclamando seus direitos e seu status como cidadãos americano-estadunidenses. Estes vídeos e variadas outras formas de expressões midiáticas ${ }^{13}$, tais como os trabalhos visuais de Julio Salgado, sinalizam uma mudança nos debates sobre imigração no país, sendo difundidos na internet e tendo ampla cobertura na mídia jornalística, transformando o slogan "Undocumented, Unafraid, Unapologetic" (em uma tradução: "indocumentados, sem medo e sem remorsos" ${ }^{14}$ ) em um dos principais motes do movimento.

Os eventos em torno do DREAM Act pareciam ser uma forma de continuidade dos recorrentes protestos a favor da reforma imigratória nos Estados Unidos que ocorreram em $2006 \mathrm{em}$ diversas cidades californianas e em outras partes do país. Desde ao menos a segunda metade da década de 2000 o governo, senado e o congresso vêm acenando a possibilidades de incorporação e de direitos civis para os imigrantes indocumentados residentes no país. O ápice destas manifestações ocorreu em 2006 em eventos massivos organizadas pelos movimentos pró-imigração que se mobilizaram na Califórnia em cidades como Los Angeles e San Francisco. Os protestos foram uma forma de resposta coletiva à proposta legislativa H.R. 4437 (The Border Protection, Anti-terrorism, and Illegal Immigration Control $A c t)^{15}$, uma proposição de lei que elevaria penalidades legais relativas à 'imigração ilegal' e classificaria como criminosos imigrantes indocumentados ou quaisquer pessoas que auxiliassem na entrada de imigrantes no país por meios não-legais. Os protestos contra a proposta de lei também potencializaram outros debates e reacenderam discussões nacionais sobre a reforma imigratória e sobre a necessidade de legislações mais liberais no que dizia respeito aos imigrantes nos Estados Unidos.

Como parte de uma campanha nacional e como forma de apoio aos movimentos e protestos naquela ocasião, no dia 28 de abril de 2006 diversas rádios voltadas para a programação de

12 Vídeo intitulado "Promo March 10, 2011 - Coming Out - Undocumented, Unafraid, Unapologetic" Acessível em : https://www.youtube.com/watch?v=jPNlpzykojE. Acessado em maio de 2015.

13 Os usos das mídias e de outras formas de comunicação online são analisados pelo/as estudioso/as tais como John Postil (2011 e 2014), Jeffrey Juris e Alex Khasnabish (2013), Rossana Reguillo (2008), Guiomar Rovira Sancho (2013) e Manuel de Castells (2012). Embora estes debates teóricos não sejam aqui abordados, em função do reduzido espaço que o formato de um artigo proporciona, estes autores e suas contribuições são importantes referências no que se refere à análise antropológica sobre os modos de resistências possíveis através dos universos midiáticos e da internet no contemporâneo.

$14 \mathrm{O}$ título do presente artigo alude ao slogan ("indocumentados, sem medo e sem remorsos") definido no movimento pró-migratório daquele momento, tendo também se transformado em uma das palavras de ordem e conteúdo de um dos projetos artísticos de Julio Salgado, tal como veremos a seguir.

15 A proposta de lei foi aprovada no Congresso em 2005, mas não foi aprovada no Senado estadunidense. 
música latino-americana nos país reproduziram o 'Nuestro Hymno' (Nosso Hino), uma versão em espanhol do hino nacional estadunidense ('The Star-Spangled Banner') lançada pelo produtor britânico Adam Kidron. Esta nova versão do hino também foi cantada em uma das maiores manifestações de protesto contra aquela proposta de legislativa, ocorrida em Los Angeles no mês de março e reunindo mais de 500 mil pessoas. Em resposta, o então presidente George W. Bush declarou em diversos meios de comunicação que o hino não deveria ser cantado em qualquer outra língua que não o inglês e que quem quisesse 'fazer parte' da nação americana deveria aprender o inglês para cantá-1o ${ }^{16}$.

A controvérsia em torno da readaptação e tradução do hino nacional estadunidense para o espanhol se estendeu de forma a criar polêmicas sobre a inserção da/os latina/os nos Estados Unidos e sua influência nos rumos e no imaginário sobre a nação. Estas manifestações massivas e o canto recriado em espanhol evidenciavam as maneiras pelas quais manifestações de rua performam e articulam significados poderosos, principalmente quando buscam manipular e reinventar símbolos nacionais tais como as bandeiras e os hinos nacionais. Tal como sugerem Judith Butler e Gayatri Spivak, as manifestações introduziam um debate sobre as pluralidades no interior da nação, um problema concernente ao 'nós' e ao 'nosso': a quem este hino pertence? (Butler e Spivak 2007: 58). As disputas em torno do hino e em torno de outros símbolos nacionais ou mesmo a afirmação de que os imigrantes indocumentados também são americanos/estadunidenses expressavam um problema em torno dos processos de pertencimento. Ao questionar quem é e quem não é incluído no 'nós' e no 'nossa' ao qual nos referimos quando nos debates sobre quem faz parte da nação, se realocam também debates sobre igualdade, cidadania, direitos civis e liberdade. Seria também então uma maneira de

repensar certas ideias de uma democracia do sensível [e perfomativa], da articulação estética no interior da esfera política, e a relação entre canção e o que é chamado o "público". Certamente que o canto [do hino] toma lugar nas ruas, mas as ruas também são expostas como lugares nos quais aqueles que não são livres para manifestar-se, livremente o fazem. Eu quero sugerir que isso é precisamente o tipo de contradição performativa que não conduz a impasses, mas sim a formas de insurgência. [...] Neste ponto o hino pode ser entendido não somente como expressão de liberdade ou desejo de incorporação - ainda que seja, claramente, as duas coisas - mas também reencenando a rua, encenando liberdade de reunião, precisamente quando e onde é expressamente proibido por lei. (Butler e Spivak 2007: 62-64)

Trata-se no fundo de um debate sobre quem pode desfrutar de certas liberdades democráticas para reivindicar certos direitos e aqui, no caso, o direito de pertencer à nação e o direito a ter direitos cívicos e políticos. Este debate se desenvolve num questionamento a respeito das próprias definições do que seja a nação em si mesma, de uma forma que reiteram ao mesmo tempo em que expandem e questionam os imaginários vigentes sobre a nação estadunidense. As próprias demandas por direitos, materializadas nestas performances culturais, são uma maneira de eficazmente discutir mudanças sociais e potencializar agências, mesmo que paradoxalmente não garantam os direitos que estão sendo reivindicados. Mas ainda assim produzam ruídos e contribuíam com os processos de mobilização e aquisição destes mesmos direitos nos debates realizados em esfera pública.

Estas performances poderiam ser tomadas por alguns como novas formas conservadoras, expressões de processos nacionalistas, ou mesmo movimentos acríticos de assimilação direta à nação em seus moldes burgueses neoliberais, algo que seria profundamente preocupante, consi-

16 As declarações do então presidente George W. Bush foram também noticiadas pelo New York Times na ocasião: http://www.nytimes.com/2006/04/28/us/28cnd-anthem.html. Acessado em abril de 2015 
derando a matriz belicista e imperialista presente em muitos dos ideais nacionalistas estadunidenses. Mas, segundo Butler e Spivak (2007: 69), este parece não ser o caso, justamente porque, ao mesmo tempo em que não se saibam quais os rumos que os movimentos pró-imigratórios possam tomar em termos de adesão aos ideários conservadores imperialistas, ao reivindicaram a 'nação americana' como seu lar e a incorporação dos imigrantes como 'autênticos' cidadãos americanos, ao cantarem o hino nacional em espanhol e ao performarem outras manifestações artísticas que incorporam as lutas pró-imigratórias, estas performances culturais podem simplesmente estar provocando uma "quebra" nestes mesmos discursos sobre a nação em seu sentido mainstream institucionalizado. Podem assim provocar disputas e descentrar a própria ideia de "nação americana" - e assim instituir uma fratura na qual dificilmente quaisquer discursos nacionalistas mais conservadores possam se (re)instaurar.

Tratar-se-ia talvez de um processo de desidentificação com os ideais de "nação americana" institucionalizados que, como na definição de José Muñoz (1999: 01), possa permitir a existência de performances e a vivência de sujeitos minoritários que se identificam ao mesmo tempo em que diferem das concepções em torno do "cidadão americano" e das noções standard acerca da nação. Estas performances permitem que se possa imaginar um mundo onde vidas, políticas e possibilidades queer e imigrantes sejam representadas em sua complexidade, e que possam ainda incorporar contradições nos imaginários sobre a nação, ao materializar e situar espaços sociais e históricos em que sujeitos conquistam e potencializam sua agência social na esfera pública.

O processo de desidentificação ali acionado, neste sentido, é uma forma de se relacionar com ideologias dominantes, sejam estas sobre a nação, sobre o binarismo de gênero e sobre noções essencialistas a respeito das classificações raciais, por exemplo. Seriam modos de desidentificação que "nem opta $[\mathrm{m}]$ por assimilar-se no interior destas estruturas ou estritamente se opor a elas; em vez disso este é um processo que trabalha com/através e contra ideologias dominantes" (Muñoz 1999: 11). De uma maneira performativa, cantar o hino nacional em espanhol, protestar pela inclusão dos imigrantes e por seus direitos civis e criar projetos artísticos que relacionem processos identitários interseccionais e migratórios podem ser formas ambivalentes e desidentificantes de inventar outras maneiras de estar no mundo e de pensar sobre a nação, em termos mais voláteis e imaginativos, potencializando agências e transformando, no processo, as relações sociais e as subjetividades. Como observaremos, o slogan "Undocumented, Unafraid, Unapologetic" também foi incorporado nos trabalhos de Julio Salgado, que incluiu o mote como processo relacionado à sua própria subjetividade, ressaltando aí as discussões sobre a sexualidade e criando o que definiu como o projeto "I am Undocuqueer".

\section{"I AM UNdOCUQUEER": PERFORMANCES CULTURAIS E PRÁXIS ESTÉTICAS UQUEER OF COLOR»}

Ao longo dessas mobilizações nacionais, o poder das imagens e da arte inserida e problematizando contextos políticos não foi menosprezado. As criações visuais do artivista Julio Salgado se tornaram um dos símbolos do movimento DREAM Act pró-imigratório, assinalando a diversidade nessas mobilizações, especialmente no que se referia à representação das populações imigrantes jovens sem documentos, queers ou transgêneros, geralmente filhos e netos de imigrantes, ou então que imigraram muito jovens, ainda quando crianças ou adolescentes, sendo socializados predominantemente nos EUA. 
A repercussão do movimento em torno DREAM act, como mencionado, desenvolveu-se através de iniciativas de organização e trabalho político entre imigrantes indocumentados nos Estados Unidos ao longo de muitos anos, algo que influenciou decisivamente a criação artística de Julio Salgado. Neste contexto, o trabalho deste artivista capturou muito dos dilemas que estudantes universitários indocumentados enfrentam cotidianamente, além de incorporar muito do trabalho político que tem sido realizado entre o ativismo Chicana/o e/ou Latina/o na região nos últimos anos. Muitas de suas imagens, replicadas continuamente na internet, especialmente em redes sociais, blogs e em sites como tumblrs e em outros suportes de mídia digital jornalística, foram utilizadas por pessoas passando geralmente por situações e frustrações semelhantes, ao serem estas pessoas também jovens, com formação universitária, imigrantes e sem papéis e com dificuldades de encontrar trabalho ou mesmo de expressar sentimentos de estranheza quando buscam problematizar seu status enquanto indocumentados. Este mesmo público tratou de transformar o trabalho de Julio, especialmente voltado para as populações queers, num dos emblemas destas mobilizações em diversas partes do país. A interseccionalidade destas lutas parece ser uma questão central nas concepções do artista, que comenta:

Eu acredito que arte tem um grande impacto na cultura e na política. Eu quero honrar o pessoal que está fazendo um trabalho maravilhoso, o pessoal jovem que está fazendo um trabalho maravilhoso e que me deram a coragem para sair das sombras como uma pessoa indocumentada e eu quero honrá-los com arte. $\mathrm{Na}$ realidade eu "saí do armário" duas vezes: uma como indocumentado e também como pessoa queer e é interessante a interseccionalidade entre as duas identidades. [...] Desde então eu tenho "saído do armário" duas vezes e tentado explicar para as duas comunidades, tanto queer como imigrante, a importância de intersectar as duas identidades e também de unir, por que nós podemos empoderar uns aos outros neste sentido. (Salgado 2012, s/p.)

Um dos trabalhos de Julio tratava justamente de dar visibilidade à juventude queer imigrante e indocumentada no interior dos debates sobre as políticas de imigração e se intitulava "I am Undocuqueer", tendo se iniciado em 2012. O projeto fazia parte de uma iniciativa mais ampla, o Queer Undocumented Immigrant Project (QUIP), e consistia em ilustrações de pessoas jovens queer e indocumentados que em sua trajetória ativista escolheram "sair das sombras" e começaram a discutir publicamente seu status imigratório, sem esconder sua situação legal como se fosse algo vergonhoso ou encoberto por culpa.

O projeto buscava discutir, com pequenos depoimentos das pessoas representadas, com diferentes perspectivas e configuradas junto às suas imagens desenhadas (sempre representadas em cores fortes e em alto contraste) ${ }^{17}$, o que significava ser indocumentado, queer e jovem nos Estados Unidos na década de 2010. Em chamadas virtuais e presenciais, Julio requisitava que cada pessoa representada pudesse dar um pequeno depoimento sobre suas experiências e vivências como indocumentado e queer. Os depoimentos seriam incorporados no desenho a ser realizado pelo artista, que eram representadas do modo gráfico e em cores florescentes bastante fortes, contando com superfícies pictóricas chapadas em cores contínuas (semelhantes às cores vivas em uma gravura em serigrafia), de superfície uniforme e contendo traços em cor negra bem demarcada, característica do traço e do estilo artístico de Julio Salgado. Geralmente os sujeitos representados se apresentavam em posições corporais alertas e ativas, quase sempre sorrindo e com a presença do depoimento da pessoa representada escrito em inglês na lateral do retrato realizado. As imagens ganhavam sua materialidade através de pinturas, cartazes, murais e em suas versões reeditadas para o universo online, com versões que se distribuíam por sites e

17Conferir as imagens e mais informações sobre o projeto no website do artista, no seguinte link: http://juliosalgado83.tumblr.com/post/16053458352/i-am-undocuqueer-is-an-art-project-in. Acessado em maio de 2015. 
outras redes sociais.

Assim, no universo virtual, e não somente em exposições de arte, como veremos mais adiante, estas imagens ganhavam potência ao darem conta destas dinâmicas sociais presentes nestes movimentos sociais, buscando trabalhar com um chamado que visava intencionalmente reclamar orgulho e empoderamento como parte da reivindicação de direitos nas ruas e nos espaços artísticos. São formas de orgulho que estão presentes nos depoimentos das pessoas representadas em uma das imagens do projeto de Julio, tal como no depoimento de Tania, que afirma:

Eu acredito que toda vez que nós "saímos do armário" com indocumentados ou undoc-queer nós estamos declarando que temos o direito de viver, aprender, trabalhar, viajar e amar sem medo. Eu preciso dizer as palavras que por grande parte da minha vida me fizeram temer, constrangida, assustada $-\mathrm{E}$ eu as reivindico como minhas! Eu sou indocumentada, latina e queer e me sinto bem em dizer isso. (Tania, no corpo da imagem) ${ }^{18}$

No ano de 2013, em uma parceria com a Galeria de La Raza, localizada no tradicional bairro Mission em São Francisco - onde a maior parte da população de origem latina reside, encoberta de murais e grafites que aludem à cultura chicana da região - e em uma das instituições que mais se dedica às manifestações artísticas relacionadas às comunidades latinas na cidade, Julio fez parte do Digital Mural Project, um programa de arte pública do espaço expositivo que busca expor diferentes murais gerados através de imagens computadorizadas ${ }^{19}$. Ocupando uma grande parede lateral na Rua Bryant, na parte externa do edifício em que se encontra a galeria, o mura ${ }^{20}$ reunia variadas ilustrações representando os undocuqueers. $\mathrm{O}$ mural remetia e dialogava com as tradições mexicanas de muralismo na sua persistência como arte pública, potencializadora de debate político através das imagens, presentes quase sempre em lugares de grande circulação de pedestres, como formas de realocar na esfera pública certas discussões políticas. Como maneira de tornar as imagens mais poderosas e potencialmente emocionantes, Julio ressaltava $^{21}$ que a escolha em representar pessoas reais com seus depoimentos tratava de trazer a frente dos debates sobre o DREAM act os aspectos relacionados à diversidade de sujeitos queer e transgêneros presentes nestas mobilizações pró-imigratórias, destacando as lideranças chaves no movimento social e dando-lhes maior presença nas disputas nacionais sobre as políticas de imigração no país. Não por acaso, muito dos undocuqueers estavam à frente da organização dos atos mais radicalizados desempenhados até então e que traziam atenção ao DREAM act como tópico de debate público nacional.

Estas performances políticas e artísticas podem ser entendidas de uma forma dupla, tal como uma ação eficaz no terreno das práticas culturais - ela mesma efetiva naquilo que diz respeito ao comentário e possível transformação que pode provocar acerca de variadas relações sociais - como são também performances culturais de pertinências artísticas, engendradas pelos artistas envolvidos com estes movimentos sociais, que incorporam em seus trabalhos aspectos

18Conferir o depoimento em inglês presente na imagem neste link: http://41.media.tumblr.com/tumblr_lxzf9m2CcR1qk61mzo1_1280.jpg. Acessado em abril de 2015.

19 Nestes vídeos produzidos pelos coletivos Dreamers Adrift Julio apresenta em um vídeo descontraído o mural realizado em parceira com a Galeria de La Raza : https://www.youtube.com/watch?v=1VhWAx3lizs (título do vídeo: "Julio's First Billboard"). Acessado em abril de 2015.

20 Conferir o material de divulgação da Galeria e uma foto externa do mural nos seguintes endereços eletrônicos: http://www.galeriadelaraza.org/eng/events/index.php?op=view\&id=4344 e http://eltecolote.org/content/news/ undocuqueer-julio-salgado-on-art-and-identity/. Acessados em abril de 2015.

21 Conferir a descrição sobre o projeto no seguinte link: http://juliosalgado83.tumblr.com/post/15803758188/i-am-undocuqueer-is-an-art-project-i. Acessado em abril de 2015. 
políticos enquanto parte de suas criações de maneira bastante intencional. Ao lidar e manipular elementos estéticos e simbólicos na criação de um trabalho que reúne simbioticamente arte e ativismo artistas como Julio dão forma ao que chamam de artivismo, algo que busca inevitavelmente também transformar e influenciar o social. Seria então

[...] uma transição na própria maneira de conceituar a categoria performance ao longo de sua elaboração no campo de estudos antropológicos e artísticos. (...) Passa-se a considerar e observar eventos em contextos culturais contemporâneos e diversos, ampliando o âmbito de possibilidades de análise, tomando-os não somente como sistemas de representação, mas também [...] processos performáticos relacionados à prática social. (Ferreira e Silva 2011: 368)

Estas performances culturais são pensadas de uma forma intimamente relacionada às práticas socioculturais, isto é, maneiras ambivalentes e táticas de sobreviver como queers of color indocumentados nos Estados Unidos, performando (des)identificações com certas representações acerca da 'nação americana' e com certas classificações raciais e étnicas nas quais estes mesmos sujeitos se compreendem enquanto indivíduos. De uma forma tática, as posições de sujeitos e as identificações aqui não são posições fixas e essencializadas, mas sim modos ambíguos de performar desidentificação no dia-a-dia, em práticas coletivas e colaborativas através da intervenção artística com e através de movimentos sociais. Talvez, como sugere Guillermo Gómez-Peña, estas performances sejam

"território" conceitual com tempos e fronteiras flutuantes. Um lugar onde a contradição, ambigüidade e o paradoxo são não somente tolerados, mas encorajados. [...] Ao contrário das fronteiras forçadas de uma nação/estado, as fronteiras do nosso "país performativo" estão abertas, dando bem-vindas para os nômades, migrantes, híbridos e párias. (Gómez-Peña 2004: 85).

\section{"ARTiVisiM: We are American" - Táticas artivistas para se (Des)identificar}

A circulação virtual das obras de Julio Salgado e das discussões realizadas pelo movimento em torno do DREAM Act culminou em uma exposição relâmpago, com a duração de somente um dia, chamada ARTIVISM: We Are American, realizada em 26 de junho de 2013. Poucos dias antes, naquele mesmo mês, o presidente Barack Obama tinha anunciado que seu governo iria conceder reconhecimento administrativo para os jovens imigrantes elegíveis pelo DREAM Act, o que possibilitaria que estas pessoas pudessem trabalhar e conseqüentemente seguissem morando nos Estados Unidos por tempo determinado.

A exposição tinha sido idealizada como uma maneira de ressaltar as conquistas do movimento em torno das recentes iniciativas governamentais contando ainda com conversas sobre arte, cultura e imigração na região da Baía de San Francisco. O evento foi organizada no Centro Cultural La Peña, na cidade de Berkeley, uma famosa organização sem fins lucrativos local, reduto voltado à difusão e reconhecimento das diferentes tradições culturais e étnicas existentes na região, na sua interface com movimentos sociais contemporâneos. $\mathrm{Na}$ ocasião, a exibição reunia diferentes trabalhos de Julio Salgado e textos de Jose Antonio Vargas, contando ainda ao longo dos debates e da exposição com a participação e mediação da artista Favianna Rodriguez, que estava também profundamente envolvida com as lutas imigrantes no país naquele momento. 
O projeto "I am Undocuqueer", de Julio Salgado, que estava presente como um dos trabalhos que compunham a exposição, ilustra uma das formas pelas quais é possível pensar sobre o artivismo em conexão com outras demandas sociais por cidadania e direitos no século XIX. Em um vídeo ${ }^{22}$ produzido pelo site CulturalStrike, Julio discute como, na realização de sua arte, ele distingue uma relação simbiótica entre arte e ativismo, algo que não está necessariamente definido somente pelo universo institucional da arte, mas também por uma estética que é relacional (Bourriaud 2009) e ao mesmo tempo potencializadora de agência daqueles envolvidos em sua realização (Gell 2001). Seu trabalho trata de fomentar transformação social através do que se define como artivismo, prática política e de criação que visa potencializar e visibilizar os processos de subjetivação e as posições de sujeitos transfigurados através de práticas artísticas.

Na junção das palavras "arte" e "ativismo", advoga-se pela indissociável relação entre fazer artístico e prática política em trabalhos que se distinguem como "tipos de criações visuais e estéticas realizadas por indivíduos que articulam e enxergam uma relação orgânica entre arte e ativismo" (Sandoval e Latorre 2008: 82). Como processos participativos, estas são maneiras de trazer à tona outras formas de resistência, modos de combate que visibilizam as lutas queer como parte do movimento pró-imigratório. Ao mesmo tempo buscam transfigurar novas agências e performances que ocupam e reatualizam "o espaço público com focos voltados para questões de abrangência coletiva e comunitária, impulsionando formas de (fazer) política diferenciadas" (Ferreira e Silva 2011: 368). A relação entre arte e organização política para mobilizações e mudança social é algo conscientemente engendrado nos trabalhos do artista, que define essa relação, em suas palavras, em uma entrevista dada ao site CulturalStrike:

\begin{abstract}
Eu penso que a importância de arte e de organização cultural é chave, por que nós enquanto artistas estamos de certo modo num lugar singular e único para re-imaginar estas questões e como nós podemos retratar estas questões de uma forma mais digna. Então arte é muito importante e chave nos modos como nós lidamos com estas questões, por que nos permite literalmente pintar uma imagem de algumas de nossas realidades. Então eu penso que isso seja realmente importante. (Salgado 2012: s/p.)
\end{abstract}

As performances artivistas aqui analisadas são tanto as manifestações de rua dos movimentos sociais pró-imigração, ao reinventarem o hino nacional estadunidense cantado em espanhol, como também são as imagens impressas e digitais criadas por Julio Salgado, como parte de seu projeto artístico que busca ressaltar o papel dos ativistas queers indocumentados nestes movimentos sociais. A potência destas performances está justamente na sua efetividade ao captarem, no momento presente, a força política e simbólica de certas práticas, como afirma o estudioso Rivera-Servera (2004). Como sugere este autor, estas práticas são "o lugar onde o aspecto presencial da performance - a sua capacidade de fazer alguma coisa - e a versatilidade da improvisação - a possibilidade de transformação e mudança - tornam-se as forças motrizes” (Rivera-Servera 2004: 273).

As manifestações pró-imigratórias e o projeto I am Undocuqueer criam espaços nos quais os queer indocumentados podem não somente come out of the shadows ("sair das sombras") reivindicando a esfera pública e o direito de reivindicar direitos, mas também são os espaços nos quais seja possível configurar e presentificar corpos e sujeitos queer não imagináveis em certas representações hegemônicas, presentes no interior dos próprios movimentos sociais pró-imigratórios, representações estas geralmente marcadas por ideais nacionalistas e heterosexistas

22 O curto vídeo intitulado "Julio Salgado and Favianna Rodriguez - CultureStrike 2012" pode ser acessado no seguinte link: https://www.youtube.com/watch?v=7dFAYEK--Lc. Acessado em abril de 2015. 
bastante destacados.

Estas performances em si mesmas, nas trocas e presentificação que elas engendram por meio de imagens, depoimentos e através dos corpos queers reunidos e visíveis em grandes manifestações públicas, constituem potencialidades e posicionalidades que "articulam, mostram e ostentam sexualidades queer publicamente, ao mesmo tempo em que engendram para estes sujeitos outras formas alternativas da latinidad, que incorporam atitudes queer no que se refere aos marcadores de gênero e sexualidade" (Rivera-Servera 2004: 274). Ramón Rivera-Servera elabora como a latinidad pode ser uma maneira de aglutinar diversas populações imigrantes de diferentes origens nacionais e étnicas:

Latinidade como um marcador de identidade tem, na última década, se tornado um emblema centralizador e estratégico para a mobilização das populações descendentes de países latino-americanos nos Estados Unidos. Muitas vezes substituindo categorias mais localizadas como Cubano-Americano, Chicano, ou Nuyorican e marcando uma diferença em relação aos rótulos homogeneizantes institucionalmente impostos, tal como Hispânico. Latinidad surge como uma bandeira de coalizão na política contemporânea dos Estados Unidos, que busca criar pontes entre comunidades Latina/os através de origens nacionais e ascendências, histórias e condições de chegada e deslocamento, e identificações raciais/étnicas.

O autor nota como a latinidad pode constituir um sentimento de pertencimento e localização, ainda que mediado muitas vezes por um sentimento de estranheza e deslocalização, provindo de experiências de vida marcadas pela marginalização social:

Como tal, latinidad oferece um lugar para identificação investida na articulação de diferença a partir de uma posição crítica, que aborda a marginalidade das populações Latina/os em relação à cultura dominante dos Estados Unidos. Latinidad constitui uma intersecção ou um lar para uma comunidade diversa de milhões que continua a ser significativamente desprivilegiada nas economias materiais, sociais, econômicas e culturais dos EUA. O pressuposto deste imaginário social pan-Latino não é exclusivamente resultado de uma afirmação política estratégica, mas é também o surgimento de uma sensibilidade, um sentimento de localização (placeness) compartilhada, e às vezes deslocalização (placelessness), no interior imaginário nacional dos EUA. Essa sensibilidade é, em parte, o produto da circulação global da cultura popular Latina/o através de redes de mídia, mas, o mais importante, é o resultado de experiências semelhantes de marginalidade. (Rivera-Servera 2004: 274)

Tal como se observa nas imagens produzidas por Julio Salgado aqui descritas, com incorporação de depoimentos de queer indocumentados em seu trabalho, ele trata de materializar um tipo de performance cultural que potencializa eficazmente a presença destas lideranças, contextualiza seus sentimentos de marginalização e estranheza, e ao mesmo tempo em que disputa de forma presente os rumos e reivindicações no interior do movimento pró-imigratório, construindo outras maneiras de repensar a nação e as próprias concepções em torno da latinidad. O que se materializa é a habilidade destas imagens de provocarem e fazerem algo em termos transformativos, em sua possibilidade de modificar estruturas e percepções sociais sobre estes sujeitos.

Aqui também então o que estaria ocorrendo seria um processo de (des)identificação com certas concepções hegemônicas de latinidad, ao mesmo tempo em que se instauram outras tantas representações a respeito dessa categoria no interior das políticas de identidade ali em jogo. Estas seriam então também maneiras de criar comunidades interseccionais através e considerando ali as diferenças intrínsecas (comunities-in-difference) (Muñoz 1999), pensando em seus significados de forma recodificada, que possam ser reinventados com novos significados. 
Tal como aponta José Muñoz, a

desidentificação é sobre reciclagem e sobre o repensar de significados codificados. O processo de desidentificação embaralha e reconstrói a mensagem codificada de um texto cultural de uma forma que tanto expõe as maquinações universalizantes e excludentes codificadas da mensagem e reprograma seu funcionamento para dar conta, incluir e capacitar identidades minoritárias e identificações. Assim, desidentificação é um passo além, é mais do que rachar o código da maioria; ele passa a usar esse código como matéria-prima para a representação de posicionalidades ou políticas desempoderadas que tenham sido instituídos como impensáveis pela cultura dominante. (Muñoz 1999: 31)

O processo de criar novos significados através de matérias-primas provindas de ideologias dominantes (sejam estas as ideologias nacionalistas imperialistas estadunidenses ou as acepções mais heterosexistas de latinidad) se visualiza melhor na criação de novas categorias que permeiam os processos identitários destes sujeitos em sua inserção no movimento pró-imigratório. Esse também é o caso dos novos termos engendrados no interior destes movimentos e também no trabalho de Julio Salgado, tal como "I am Undocuqueer". O termo "undocuqueer" é em si justamente um neologismo em língua inglesa que busca adicionar as palavras undocumented (indocumentado) e queer, criando uma noção interseccional que expressa um tipo de justaposição de diferentes marcadores de diferença, em termos de gênero, sexualidade, raça/etnicidade e status imigratório, ao mesmo tempo em que denota um conjunto de desigualdades sociais e econômicas relacionadas a estas posições de sujeito (Foucault 1995: 231) nos Estados Unidos sem necessariamente hierarquizá-las.

As diversas definições provenientes de instâncias governamentais (tal como illegal aliens) para denominar estes sujeitos não dão conta das experiências e das classificações empíricas desenvolvidas por estas pessoas para englobar seus processos e das suas políticas identitárias e de subjetivação. As categorias queer, indocumentado e imigrante "representam categorias de identidade contestadas. [...] Ser latino, queer, imigrante e indocumentado é ocupar uma posição singular nos Estados Unidos" (Messer 2010: 12), uma posição que contesta e desafia os marcadores de diferença relativos a sexo, sexualidade, raça e etnicidade prevalecentes no país, em uma dinâmica cotidiana de luta e, muitas vezes, de estranheza.

A configuração desse novo termo, undocuqueer, que agrupa duas destas categorias de identidade e catalisa ainda outros tantos processos de desidentificação presentes nas dinâmicas do movimento social e nas vivências destes sujeitos, atesta as maneiras pelas quais agências podem ser potencializadas através de imagens e performances artivistas eficazes assim como se constituem também enquanto táticas de resistência queer (Messer 2010: IV) frente às ideologias hegemônicas, que disputam e reorganizam a esfera pública e os debates sobre migração na maior potência imperialista mundial. Disputar certas políticas identitárias queer no interior do movimento pró-imigração nos EUA é uma maneira de reconfigurar e repensar os espaços nas práticas culturais, sejam estes virtuais ou nas ruas ocupadas por massivas manifestações de protesto. A série artivista de Julio se torna uma das formas que as táticas de resistência queer podem tomar, ao ressaltarem as dificuldades que muitos imigrantes indocumentados e queer enfrentam cotidianamente, não somente pelo fato de serem imigrantes, mas também pelo racismo que ainda permeia as vivências destas populações de queer, lésbicas e transgêneros existentes em grandes cidades e "mecas" LGBTQI, tal como a cidade de São Francisco e também pela homofobia e transfobia que ainda presenciam no interior de movimentos sociais progressistas. 
O trabalho de Julio Salgado encampa de forma aberta e irreverente os debates nacionais sobre as políticas imigratórias nos Estados Unidos, mas também adentra no terreno das relações interpessoais através dos depoimentos muito sucintos e poderosos de pessoas reais que o artista representa. Muitas destas dinâmicas e depoimentos revelam algumas das disputas sobre os rumos e predominância dos queer indocumentados no interior dos movimentos pró-imigratórios nos EUA ao mesmo tempo em que se constituem seus espaços (físicos e virtuais) no interior destas mobilizações. Contribuindo com debates sobre a imigração e sobre a visibilidade das populações que se autodefinem como queer of color, os trabalhos de Julio Salgado trazem à tona as possibilidades de pensarmos sobre maneiras de realizar discussões nem sempre fáceis sobre sexualidade, gênero, etnicidade e de outros marcadores de diferenças no interior de movimentos sociais nas suas busca por direitos civis e cidadania no século XXI.

\section{REFERÊNCIAS}

Bourriaud, Nicolas. 2009. Estética relacional. São Paulo: Martins Fontes.

Butler, Judith, e Spivak, Gayatri. 2007. Who sings the nation-state? Language, politics, belonging. London: Seagull.

Castells, Manuel. 2012. Networks of Outrage and Hope: Social Movements in the Internet Age. Cambridge and Malden, MA: Polity Press.

Ferreira, Glauco. 2012. "QWOCMAP: (auto)representações de mulheres queer e de cor e sua produção audiovisual nos EUA”. Revista Ártemis, João Pessoa: UFPB, v. 14, ago./dez, Pp. 68-86.

e Silva, Renata Ferreira. 2011. "Praia 43: performance e a(r)tivismo". Revista Ouvirouver (Online), v. 7, Pp. 354-371.

Foucault, Michel. 1995. "O sujeito e o poder". In: RABINOW, Paul; DREYFUS, Hubert. Michel Foucault. Uma trajetória filosófica. Para além do estruturalismo e da hermenêutica. Rio de Janeiro: Forense Universitária, Pp. 231-235.

Gell, Alfred. 2001. "A rede de Vogel, armadilhas como obras de arte e obras de arte como armadilhas”. Arte e Ensaios: Revista do Programa de Pós-Graduação em Artes Visuais, Rio de Janeiro: UFRJ, ano VIII, n. 8, Pp. 174-191.

Gómez-Peña, Guillermo. 2004. "In: Defence of Performance Art”. In: HEATHFIELD, Adrian, Live Art and Performance. Londres: Tate, Pp. 76-85.

Hall, Stuart. 2000. “Quem precisa de identidade?” In: Tadeu da Silva, Tomaz (org.) Identidade e diferença: a perspectiva dos estudos culturais. Rio de Janeiro: Petrópolis: Vozes, Pp. 104108.

Juris, Jeffrey S., and Khasnabish, Alex. 2013. "Introduction: Ethnography and Activism within Networked Spaces of Transnational Encounter". In: Insurgent Encounters: Transnational Activism, Ethnography, and the Political. Juris, Jeffrey S., and Khasnabish, Alex (Eds.). Durham, N.C.: Duke University Press, Pp. 1-36.

Messer, Lucas Charles. 2010. Queer Migrant Culture: Undocumented Queer Latinos and Queer Clubs in Phoenix. Dissertation Presented in Partial Fulfillment of the Requirements for the Degree Doctor of Philosophy. Tempe (Phoenix): Arizona State University.

Muñoz, José Esteban. 1999. Disidentifications: Queers of Color and the Performance of Politics. Minneapolis: University of Minnesota Press.

Postill, John. 2011. Localizing the Internet: An Antbropological Account. Oxford and New York: Berghahn. 
.2014. "Freedom technologists and the new protest movements: a theory of protest formulas". Convergence, November, vol. 20, n. 04, Pp. 402-418.

Reguillo, Rossana. 2008. "Instituciones desafiadas. Subjetividades juveniles: territorios en reconfiguración”. Christus - Revista de Teología, Ciencias Humanas y Pastoral, no 768, Pp. $18-23$.

Rivera-Servera, Ramón H. 2004. "Choreographies of Resistance: Latina/o Queer Dance and the Utopian Performative”. In: Modern Drama, Volume 47, Number 2, Summer. Toronto: Universty of Toronto, Pp. 269-289.

Rovira, Guiomar S.. 2013. "De las redes a las plazas: la web 2.0 y el nuevo ciclo de protestas en el mundo". Revista Acta Sociológica, no 62, Septiembre-diciembre , Universidad Nacional Autónoma de México. Pp. 105-134.

Salgado, Julio. 2012. Undocumented Americans: Julio Salgado (Video). New York City: Time Magazine YouTube Channel (Time Magazine) June 14 ${ }^{\text {th, }}$ 2012. (http://migre.me/peaJd)

Sandoval, Chela, and Latorre, Guisela. 2008. "Chicana/o artivism: Judy Baca's digital work with youth of color".EVERETT, Anna (Ed.). Learning race and ethnicity: youth and digital media. Cambridge: The MIT Press, Pp. 81-108.

\section{ARtivism "Undocuqueer» Latino in the USA : QUeER, ILlEGAL, Without feAR AND REMORSE}

This article analyses artivist initiatives around pro-immigrant movements in the United States, more specifically in the San Francisco Bay Area. It address particularly the "I am Undocuqueer" project developed by the Mexican-American artivist Julio Salgado, highlighting the local ways in which contemporary social movements concerned with immigration rights in the US catalyze other ways of thinking about art and politics, especially among Latino populations, focusing on the movements and individuals who define themselves as "queer of color». Within this context, individuals are articulating local definitions around what artivism means, developing meanings that are deeply involved in a movement of reclaiming their civil rights. This also makes room for the configuration of distinct intersectional identity processes and fosters further discussion on what is actually meant by the "American nation", referring to a broad debate on citizenship in the twenty-first century.

Keywords: contemporary social movements, queer of color, artivism, modes of subjectivation

Recebido em: 2015-01-31

Aceitado em: 2015-10-06 